UNIVERSIDADE ESTADUAL DE FEIRA DE SANTANA

Autorizada pelo Decreto Federal $n^{\circ} 77.496$ de 27/04/76

Recredenciamento pelo Decreto $n^{\circ} 17.228$ de $25 / 11 / 2016$

PPPG

PRÓ-REITORIA DE PESQUISA E PÓS-GRADUAÇÃO

COORDENAÇÃO DE INICIAÇÃO CIENTÍFICA

XXIV SEMINÁRIO DE INICIAÇÃO CIENTÍFICA DA UEFS

SEMANA NACIONAL DE CIÊNCIA E TECNOLOGIA - 2020

\title{
EFEITO DO ESTRESSE SALINO NO DESENVOLVIMENTO E PRODUÇÃO DE PLANTAS DE Physalis angulata $\mathrm{L}$.
}

\author{
Viviane de Jesus Carneiro $^{1}$; Marilza Neves do Nascimento Ribeiro² ${ }^{2}$ Alismário Leite da \\ Silva $^{3}$; Francisco dos Santos Neto ${ }^{4}$ \\ 1. Bolsista PIBIC/FAPESB, Graduanda em Agronomia, Universidade Estadual de Feira de Santana, e-mail: \\ vivianedjcarneiro@gmail.com \\ 2. Orientadora, Departamento de Ciências Biológicas, Universidade Estadual de Feira de Santana, e-mail: \\ marilzaagro@ hotmail.com \\ 3. Coorientador, Mestrando em Recursos Genéticos Vegetais, Universidade Estadual de Feira de Santana, e-mail: \\ alismarioagronomo@ hotmail.com \\ 4. Graduando em Agronomia, Universidade Estadual de Feira de Santana, e-mail: franciscosantosn@ hotmail.com
}

PALAVRAS-CHAVE: camapú; crescimento; salinidade; condutividade elétrica

\section{INTRODUÇÃO}

Nativa da região amazônica brasileira (Corrêa, 1984), a Physalis angulata L., também conhecida como camapú ou juá-de-capote, apresenta ampla distribuição principalmente em regiões tropicais e subtropicais do mundo (Ligarreto et al., 2005; Souza \& Lorenzi, 2005). Com hábito de crescimento herbáceo, a espécie de ciclo anual (Rufato et al., 2008), tem despertado atenção especial em pesquisas voltadas ao estudo do seu potencial farmacológico (Santos, 2017; Onyegeme-Okerenta, 2019), em função da produção de compostos denominados de fisalinas (TOMASSINI et al., 2000).

Embora estudos sobre a espécie estejam sendo desenvolvidos, poucas são as informações relacionadas ao seu cultivo quanto ao uso de águas salinas, sobretudo na região semiárida do Brasil, onde grande parte dos solos apresentam elevados teores de sais (Ribeiro et al., 2003). Nesse cenário, a produção agrícola é amplamente prejudicada, pois nestas condições as plantas tendem a apresentar baixo desempenho em função dos decréscimos na absorção de água do meio de cultivo, além de apresentarem sintomas de toxidez, devido ao elevado teor de sais que são absorvidos pelo sistema radicular (Larcher, 2000). Esses os íons tóxicos acabam estabelecendo competição com nutrientes considerados essenciais, promovendo desequilíbrio nutricional que afeta diretamente o crescimento do vegetal (LACERDA, 2000).

Diante disso, é de suma importância avaliar o desempenho e os processos morfofisiológicos da espécie $P$. angulata submetida ao estresse salino, buscando apresentar importantes contribuições sobre o crescimento e o desenvolvimento da espécie. Dessa forma, o presente estudo teve como objetivo avaliar a influência do estresse salino no desenvolvimento de plantas Physalis angulata L por meio de índices fisiológicos.

\section{MATERIAL E MÉTODOS}

Conduzido em casa de vegetação na Unidade Experimental Horto Florestal da Universidade Estadual de Feira de Santana (UEFS), Feira de Santana-BA, o experimento foi disposto em 
delineamento experimental inteiramente casualizado, com 15 repetições, onde os tratamentos consistiram em cinco níveis de salinidade, expressos em termos de condutividade elétrica: $\mathrm{CE}_{0}: 0,0$; $\mathrm{CE}_{1}: 1,80 ; \mathrm{CE}_{2}: 3,60 ; \mathrm{CE}_{3}: 5,4 ; \mathrm{CE}_{4}: 7,2 \mathrm{dS} \mathrm{m}^{-1}$.

As plantas foram conduzidas em sistema hidropônico do tipo floating, em vasos individuais com capacidade para 6 L, utilizando a solução nutritiva proposta por Sarruge (1975). As avaliações foram realizadas após 35 dias de estresse salino, sendo estas: taxa fotossintética, número de folhas (NFOLHAS), número de frutos (NFRUTOS) e massa seca total (MST). Os dados obtidos foram então submetidos à análise de variância e de regressão utilizando o programa estatístico $\mathrm{R}^{\circledR}(\mathrm{R}$ DEVELOPMENT CORE TEAM, 2010).

\section{RESULTADOS E DISCUSSÃO}

Observou-se que a taxa fotossintética reduziu nas condutividades elétricas da solução nutritiva acima de 1,8 dS m $\mathrm{dS}^{-1}$ (Figura 1-A), sendo verificado na condutividade de 7,2 $\mathrm{dS} \mathrm{m}^{-1}$ decréscimo de 22,9\% $\left(11,32 \mu \mathrm{mol} \mathrm{CO} \mathrm{m}^{-2} \mathrm{~s}^{-1}\right)$ em comparação com plantas sem adição de $\mathrm{NaCl}(14,64 \mu \mathrm{mol} \mathrm{CO} 2$ $\left.\mathrm{m}^{-2} \mathrm{~s}^{-1}\right)$. Entretanto, na condutividade de $1,8 \mathrm{dS} \mathrm{m}^{-1}$ houve aumento de $11,80 \%\left(16,60 \mu \mathrm{mol} \mathrm{CO}_{2} \mathrm{~m}^{-2}\right.$ $\left.\mathrm{s}^{-1}\right)$ na taxa fotossintética.

Para o número de folhas, o modelo estatístico que mais se ajustou aos dados foi de ordem quadrática (Figura 1-B), indicando que ao aumentar a concentração salina, houve também uma redução considerável no parâmetro. Essa redução foi de 58,4\%, ou aproximadamente 248 folhas, ao

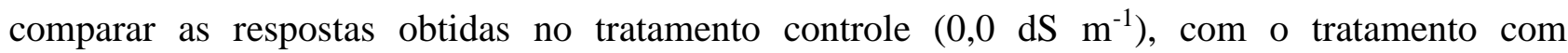
concentração de $7,2 \mathrm{dS} \mathrm{m}^{-1}$.

Já o número de frutos (NFRUTOS) (Figura 1-C), apresentou redução linear, com decréscimos mais proeminentes na maior concentração salina $\left(7,2 \mathrm{dS} \mathrm{m}^{-1}\right)$, chegando a apresentar 78,5\% de redução nessa condutividade, quando comparada ao controle $\left(0,0 \mathrm{dS} \mathrm{m}^{-1}\right)$. Para a MST, as análises também apontaram comportamento quadrático (Figura 1-D), com decréscimos a partir da concentração de $1,8 \mathrm{dS} \mathrm{m}^{-1}$. Esse decréscimo foi de $37,2 \%$ na maior concentração salina $\left(7,2 \mathrm{dS} \mathrm{m}^{-}\right.$ ${ }^{1}$ ), em comparação aos resultados obtidos na concentração de $1,8 \mathrm{dS} \mathrm{m}^{-1}$.

Figura 1. Taxa fotossintética (A), Número de folhas (B), Número de frutos (C) e Massa seca total (D) de $P$. angulata L sob estresse salino.
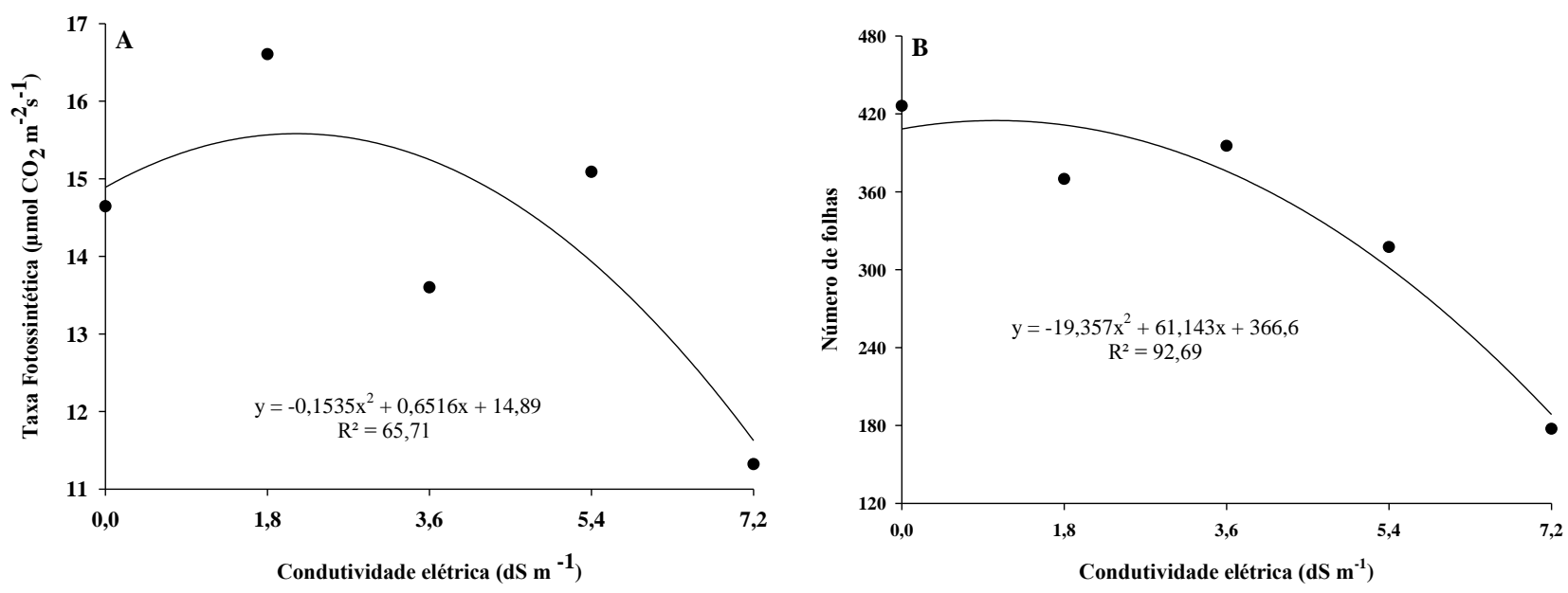

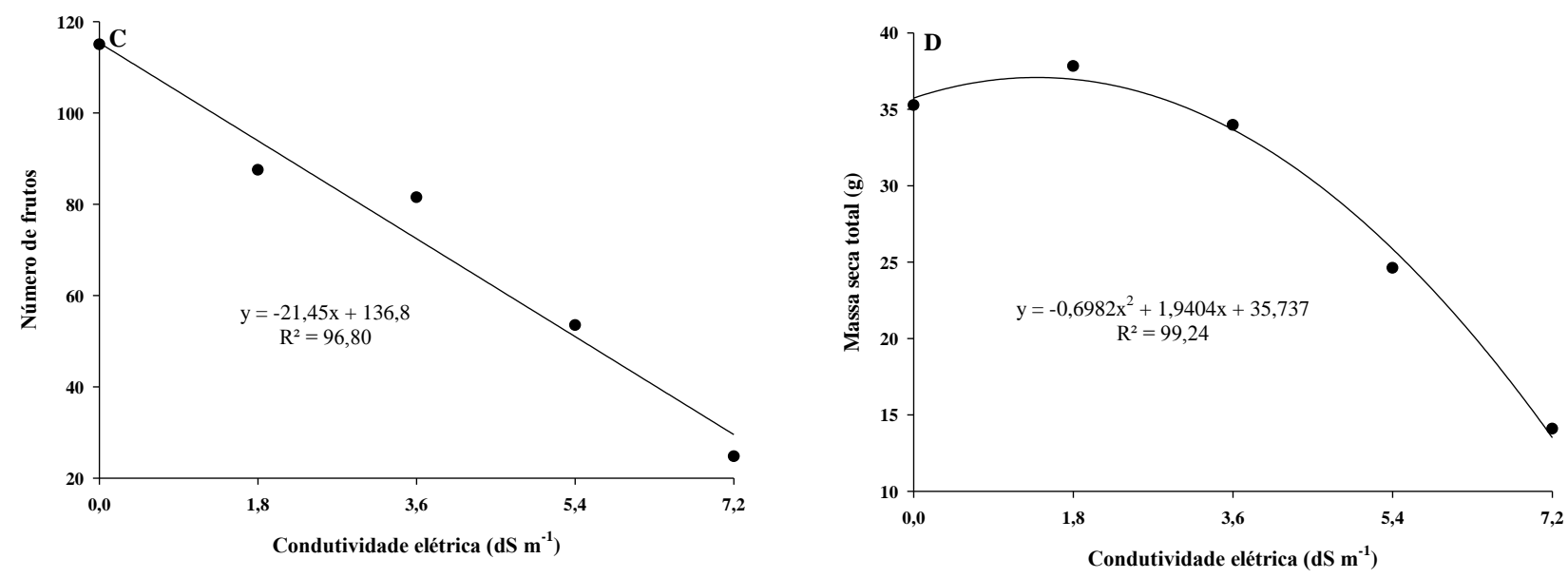

Quando os íons de sódio (Na+) e cloreto (Cl-) atingem altas concentrações, podem provocar alterações em todo o tecido vegetal (Munns \& Tester, 2008), promovendo uma acentuada redução na fotossíntese, em função da baixa absorção de água pelas plantas e consequente, fechamento estomático, visando reduzir as perdas de água para o ambiente, quando expostas a altas concentrações salinas (MELONI et al., 2003).

Além disso, a influência negativa da salinidade nos parâmetros ligados ao crescimento vegetativo, pode ser explicada devido à diminuição no alongamento e expansão celular, provocado principalmente pelo efeito osmótico e queda na turgidez celular (Jamil et al. 2007), assim como desequilíbrio nutricional e fisiológico em função dos sais em solução, promovendo principalmente a redução no acúmulo de biomassa (Taiz \& Zeiger, 2013). Nesse sentido, a planta também passa a priorizar determinados processos, a fim de evitar maiores danos ao vegetal, dando então, início a um processo de abscisão foliar e redução na produção de novos drenos, como os frutos, reduzindo assim os gastos metabólicos (Oliveira et al., 2011).

Respostas como estas também foram verificadas por Dias et al. (2018), em que foi constatado que a salinidade da água de irrigação promoveu depleção nas trocas gasosas em plantas de gergelim (Sesamum indicum). Assim como Silva et al. (2005), que analisando frutos de melão identificaram uma redução linear no número de frutos e, Oliveira et al. (2015), que verificaram efeito quadrático no número de folhas em feijão-caupi, ambos produzidos em ambiente salino.

\section{CONSIDERAÇÕES FINAIS}

A presença de sais no meio de cultivo interfere negativamente no crescimento de plantas de $P$. angulata. Entretanto, os parâmetros de taxa fotossintética, número de folhas e massa seca total demonstraram que a espécie apresenta tolerância até a condutividade elétrica de $1,8 \mathrm{dS} \mathrm{m}^{-1}$, com decréscimos acentuados em condutividades superiores.

\section{REFERÊNCIAS BIBLIOGRÁFICAS}

CORRÊA, M. P. Dicionário das plantas úteis do Brasil e das exóticas cultivadas. Ministério da Agricultura. Instituto Brasileiro de Desenvolvimento Florestal, Rio de Janeiro, vol. 02, Imprensa Nacional, 1984, 707p.

DIAS, A. S. et al. 2018. Trocas Gasosas e Eficiência Fotoquímica do Gergelim sob Estresse Salino e Adubação com Nitrato-Amônio. Irriga 23: 220-234. 
JAMIL, M. et al. Salinity reduced growth PS2 photochemistry and chlorophyll content in radish. Scientia Agricola, v. 64, n. 02, p. 111-118, 2007.

LACERDA, C. F. Crescimento e acúmulo de solutos orgânicos e inorgânicos em dois genótipos de sorgo forrageiros submetidos a estresse salino. 2000. Universidade Federal de Viçosa.

LARCHER, W. Ecofisiologia Vegetal. São Carlos-SP. Ed. Rima Arts e Textos. 531 p. 2000.

LIGARRETO, G. A.; LOBO, M.; CORREA, A. Recursos genéticos del género Physalis em Colombia In: Fisher, G. et al. Avances em cultivo, poscosecha y exportación de la uchuva Physalis peruviana L. em Colombia. Bogotá: Universidad Nacional de Colombia, Facultad de Agronomia, 2005.

MELONI, D. A.; OLIVA, M. A.; MARTINEZ, C. A.; CAMBRAIA, J. 2003. Photosynthesis and activity of superoxide dismutase, peroxidase and glutathione reductase in cotton under salt stress. Environmental and Experimental Botany 49: 69-76.

OLIVEIRA, F. A. et al. Produção de feijão-caupi em função da salinidade e regulador de crescimento. Rev. Bras. Eng. Agríc. Ambiental, v. 19, n. 11, p.1049-1056, 2015.

OLIVEIRA, F.A. et al. Desempenho de cultivares de alface submetidas a diferentes níveis de salinidade da água de irrigação. Rev. bras. eng. agríc. ambient. vol.15, n.8, 2011

ONYEGEME-OKERENTA, B. M.; ESSIEN, E. B.; ESIN, J. I. Anti-sickling Properties of Aqueous Extracts of Dennettia tripétala and Physalis angulata. Asian Journal of Biological Sciences, 2019.

R DEVELOPMENT CORE TEAM. R: A language and environment for statistical computing. $\mathbf{R}$ Foundation for Statistical Computing, Vienna, Austria, v. 0.02, 2010.

RIBEIRO, M. R.; FREIRE, F. J.; MONTENEGRO, A. A. A. 2003. Solos halomórficos no Brasil:

Ocorrência, gênese, classificação, uso e manejo sustentável.

RUFATO, L. et al. Aspectos técnicos da cultura da physalis. Lages: CAV/UDESC; Pelotas:UFPel, 2008. 100p.

SANTOS, K. S.; FLORES, E. M.; MALCHER, E. T. Caracterização química e atividade antioxidante (in vitro) do fruto do camapú (Physalis peruviana, L.). Revista Ciência e Sociedade, v.1, n.2, 2017.

SARRUGE, J. R. Soluções nutritivas. Summa Phytopathologica, v. 1, n. 03, p. 231-233, 1975.

SILVA, M. C. C.; MEDEIROS, J. F.; NEGREIROS, M. Z.; SOUSA, V. F. Produtividade de frutos do meloeiro sob diferentes níveis de salinidade da água de irrigação, com e sem cobertura do solo.

Hortic. Bras. v. 23, n. 02 Brasília, 2005.

SOUZA, V.C.; LORENZI, H. Botânica sistemática: guia ilustrado para identificação das famílias de angiospermas da flora brasileira, baseado em APG II. Nova Odessa, Instituto Plantarum, 2005.

TAIZ, L.; ZEIGER, E. (2013) -Fisiologia vegetal. 5. ed. Porto Alegre, Artmed, 918 p.

TOMASSINI, T. C. B. et al. Gênero Physalis: uma revisão sobre vitaesteróides. Química Nova. v. 23. n. 01 p. 47-57, 2000. 